\title{
Entre antigos e modernos: escrita da história e lições morais no Brasil do século XIX
}

Evandro Santos*

Resumo: O objetivo deste artigo é examinar a presença de autores antigos na produção historiográfica oriunda do Instituto Histórico e Geográfico Brasileiro (IHGB), fundado no Rio de Janeiro, em meados do século XIX. Para tanto, alguns textos publicados na Revista do $I H G B$ são retomados à luz do debate atual sobre o tema. Considerados fontes seminais para a história da historiografia, abordagem que sustenta a análise aqui exposta, tais escritos fornecem importantes elementos ao debate que se encontra aberto. Nesse sentido, argumenta-se que, a despeito de sua participação no longo processo de estabelecimento da modernidade e de sua marca tanto epistemológica quanto retórica, os aspectos morais fornecidos pelos autores antigos operaram, particularmente no caso brasileiro, como elo discursivo entre o poder do Estado imperial e a emergente disciplina histórica.

Palavras-chave: História da historiografia. Antigos e Modernos. IHGB.

"Professor do Departamento de História do Centro de Ensino Superior do Seridó CERES-UFRN. Doutor em História Pela Universidade Federal do Rio Grande do Sul - UFRGS. Esta pesquisa foi financiada pela Coordenação de Aperfeiçoamento de Pessoal de Nível Superior - CAPES. E-mail: evansantos.hist@gmail.com.

Anos 90, Porto Alegre, v. 25, n. 47, p. 253-278, jul. 2018 
Entre antigos e modernos: escrita da história e lições morais no Brasil...

\section{Introdução}

A presença de autores oriundos da antiguidade na escrita da história do Brasil, em seu sentido moderno, tornou-se objeto de análise privilegiado há poucos anos pelos historiadores. Tendo por escopo a apropriação ou a adaptação de formulações de filosofia política, das características e da própria abrangência social da religião ou de formas narrativas que resistiram à passagem dos séculos e às mudanças culturais, é incontornável a constatação a seguir: o conhecimento e o interesse por determinados modelos vindos da antiguidade fundamentaram as principais tentativas de explicação ao paradoxo da modernidade no que se refere ao particular e ao geral, ou ainda, à identidade e ao universal (PAYEN, 2011).

Discussão ampla e de interesse perene para as mais diversas áreas dos saberes humanos, o argumento a ser de imediato exposto, considerando-se o que foi dito anteriormente, é o seguinte: a escolha pela permanência do diálogo com os antigos permite verificar que a disciplina histórica não buscou estabelecer seu estatuto a partir de um rompimento com os domínios então definidos na modernidade (a política, a estética, a ciência, a moralidade etc.), mas pretendeu ocupar os diferentes espaços porquanto conquistava a autoridade que lhe era atribuída, sobretudo, a partir das primeiras décadas do século XIX (ENDERS, 2014, p. 77). Assim, defende-se neste artigo que o discurso da história fez das trocas com os autores do mundo antigo outro recurso para a abertura da ação dos historiadores nas diversas esferas da vida pública, em especial na política. Antes, porém, que aquelas filosofias da história com feições próprias da intervenção política e social estivessem em pleno domínio nos debates eruditos internacionais (remete-se aqui, principalmente, ao positivismo e ao marxismo), parte considerável do pensamento tido como adequado à vaga liberal (ou à crítica desta) e à narrativa dos passados nacionais resguardava o diálogo com os antigos nos dois lados do Atlântico (KOSELLECK, 2013, p. 119-184). 


\section{O IHGB e os deveres da história: a historicidade do regime}

Sendo inegável que as letras, além de concorrerem para o adorno da sociedade, influem poderosamente na firmeza de seus alicerces, ou seja pelo esclarecimento de seus membros, ou pelo adoçamento dos costumes públicos, é evidente que em uma monarquia constitucional, onde os méritos e os talentos devem abrir as portas aos empregos, e em que a maior soma de luzes deve formar o maior grau de felicidade pública, são as letras de uma absoluta e indispensável necessidade, principalmente aquelas que, versando sobre a história e geografia do país, devem ministrar grandes auxílios à pública administração e ao esclarecimento de todos os brasileiros (REVISTA DO IHGB, 1839, p. 5).

Se o diálogo com os antigos foi um assunto relevante para a construção do Estado imperial no Brasil pós-independência, a importância tornou-se mais marcante quando do investimento para a fundação do Instituto Histórico e Geográfico Brasileiro (IHGB), esforço da então recente instituição, no ano de 1838. Sem esquecer registros acadêmicos emergentes ainda no período em que o Brasil era a mais importante colônia portuguesa e todas as produções esparsas, contemporâneas ou não ao IHGB, o que se processou a partir da fundação desse órgão foi um projeto sistemático e resistente, de caráter propriamente nacionalista e centralizador, que atravessou os anos Oitocentos. $\mathrm{O}$ fato de o órgão dedicado à pesquisa histórica e geográfica ter surgido no seio de uma associação de caráter industrial não é fortuito, sabendo-se do ponto de vista pragmático que o desenvolvimento de tais saberes representava na época no mundo ocidental. Nesse sentido, é importante ter como fator em destaque as decisões políticas que fizeram do segundo reinado ambiente propício para a implementação do órgão dedicado à história e à memória nacionais.

É preciso que se diga de imediato: mais que um espaço dedicado à cultura da lembrança, o IHGB fora concebido como um lugar de 
estudo e trabalho político, constatação em nada antagônica à sua importância como objeto de pesquisa para uma história da historiografia tal como esta é atualmente concebida. Os homens que se dedicavam ao levantamento de nomes, eventos, objetos, obras de arte e de ciência que resistiram ao tempo eram figuras plenamente ligadas à diminuta burocracia da empresa imperial brasileira do final dos anos 1830 (WEHLING, 1994, p. 151-168). Do mesmo modo que as chamadas academias letradas da Europa no século XVIII encontravam suas bases na subvenção das monarquias, o cuidado e o controle do acervo do passado estavam paralelamente submetidos à dimensão político-administrativa de cada Coroa. ${ }^{1}$ Entretanto, é interessante observar que, a despeito da sobreposição da política no controle do órgão, a variedade de temas e assuntos que foram explorados desde o início das atividades confirma a força e o dinamismo de um conceito de história caracterizado por um sentido alargado. Por esse prisma, a conjunção entre uma ideia de história moderna, isto é, imperante em seu caráter processual e aberto, não entrava em conflito com o investimento acadêmico que vinha de séculos anteriores e auxiliava na manutenção das monarquias tradicionais e absolutistas na Europa.

A historiografia produzida pelo IHGB nasceria, por assim dizer, sob um clima dominado pelos ditames do presente, cuja novidade residia muito mais nas justificativas dadas para o interesse pelo passado. Diversas características comprovam essa afirmação. Não apenas pelo fato de ser uma empresa financiada pelo Estado imperial e pela formação e atuação de seus membros, o Instituto nasceu imbuído da ideia de que, segundo Manoel Salgado Guimarães, "[...] era preciso ver na História um ensinamento moral e a importância dos fatos narrados estava justamente na possibilidade de se extrair deles uma lição, constituí-los em fonte de exemplos, inspiração para o patriotismo" (GUIMARÃES, 2002, p. 196-197). Esse registro do presente, estrutural e estruturante do Estado moderno, é elemento que merece ser analisado, pois aí se encontra boa parte das explicações para a presença de autores antigos nos escritos do século XIX. Os antigos estavam nas falas da maioria dos primeiros sócios do IHGB. Conforme sublinha Rodrigo Turin, 
[...] a constatação dessa presença, concretizada de modo abundante na forma de epílogos, citações e comparações, indica, entre outras coisas, a familiaridade desses autores com a tradição clássica e, como ressaltou Roberto Acízelo de Souza, o importante papel que a eloquência continuava a desempenhar no Império (TURIN, 2010, p. 132).

O alargamento da concepção temporal foi favorecido, ao passo que a dimensão retórica, em movimento centrífugo, parecia atrair todo o passado no sentido do contemporâneo, havendo a valorização de um passado selecionado. A escolha de boa parte dos letrados foi aquela que dizia algo sobre o estado da "ideia de nação" em meados do século XIX. Ao Brasil, faltava uma origem distante e conhecida, algum elemento que pudesse ligar os dilemas políticos e sociais do presente. Mesmo que não fossem portadores de uma lição moral plena e acabada, os indígenas, por exemplo, na visão de Domingos José Gonçalves de Magalhães, poderiam aprender:

O elemento europeu que constitui uma parte da população do Brasil, e ao qual devemos o incremento da nossa civilização, tem por si a história gloriosa dos seus antepassados, desde que herdeiros dos remanescentes da civilização grega e romana que combateram, deixaram por este mesmo combate o estado selvagem em que viviam (MAGALHÃES, 1860, p. 6).

O passado mostrava que experiências ensinavam. Alinhar diferentes culturas em uma mesma trajetória é forma eficiente de converter fragmentos de passado, que nada têm em comum, em tradição. Quando se pensa na chamada globalização dos últimos trinta anos, pode-se ter ideia aproximada desse efeito. É permitido frisar: tratava-se de um esforço de uniformização do presente a partir do passado. Ainda sobre as considerações de Magalhães, sublinha Turin:

[...] essa posição de origem, convém ressaltar, longe de indicar qualquer condição primitiva dos antigos, qualifica-se antes pelo caráter de fundação daquilo que se entende como uma 
Entre antigos e modernos: escrita da história e lições morais no Brasil...

tradição europeia, à qual o Brasil se vincula pela colonização portuguesa (TURIN, 2010, p. 138).

Dentro da lógica das monarquias europeias do período, a visão temporalmente deslocada dos autóctones americanos parece algo evidente. Dessa maneira, não significa ser fruto de grande elucu-

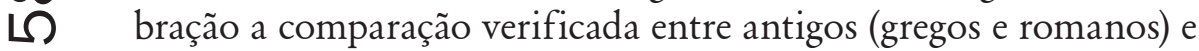
índios do Brasil, sem desconsiderar, contudo, suas consequências. O movimento de "regeneração" que tomava conta das emergentes nações da Europa buscava justamente no período medieval as bases dos seus dias então atuais (SILVEIRA; SANTOS, 2014, p. 90-104). $\mathrm{O}$ que se discutia como sendo o passado remoto da civilização europeia (antiguidade greco-romana) passava a situar a distância entre os europeus que dominavam politicamente a recente ex-colônia e os povos conquistados. A relação com os antigos era, por vezes, uma relação de controle temporal:

[...] a posse de um passado histórico, tão extenso e 'grandioso' como o das civilizações mais antigas, garantiria às sociedades americanas um critério de identificação caro à cultura histórica oitocentista através de sua inserção paralela a uma tradição (re)conhecida (TURIN, 2010, p. 140).

Na leitura de Magalhães, de 1860, a comparação e proximidade entre o caráter dos indígenas e os homens do mundo antigo construíam uma temporalidade então emprestada aos indígenas.

Tais injunções já estavam presentes desde a fundação do IHGB, como comprova o importante Discurso do cônego Januário da Cunha Barbosa, secretário perpétuo daquela agremiação. A presença dos antigos não serviria apenas como parâmetro de comparação que ajudava a explicar o mundo indígena americano e seu papel na grande história nacional, mas operaria no próprio fazer historiográfico em diferentes níveis. A cultura letrada deslocava muitos dos seus princípios fundamentais de nomes como Cícero, Plutarco e Tácito. Dessa maneira, era bastante evidente a face política do projeto historiográfico do novo órgão imperial: 
O coração do verdadeiro patriota brasileiro aperta-se dentro no peito quando vê relatados desfiguradamente até mesmo os modernos fatos da nossa gloriosa independência. Ainda estão eles ao alcance das nossas vistas, porque apenas dezesseis anos se têm passado dessa época memorável da nossa moderna história, que acrescentou no Novo Mundo um esperançoso império ao catálogo das nações constituídas, e muitos já vão se obliterando na memória daqueles a quem mais interessam, só porque têm sido escritos sem a imparcialidade e necessário critério, que devem sempre formar o caráter de um verídico historiador (BARBOSA, 1839, p. 10).

Encravado em um continente em que diversos processos de independência ocorriam por meio da força, rumo ao republicanismo, o Império do Brasil, por sua peculiaridade, ligado ao contexto português, fazia do investimento na história um diálogo legitimador da política do presente e também de sua composição geográfica, a outra face do IHGB. O critério de imparcialidade também estava condicionado ao componente nacional. Este espírito protecionista e dominante mostrava-se presente em todas as diretrizes do referido projeto historiográfico.

O clima político do Regresso apenas favorecia o que já era a estrutura do saber histórico que passaria a ser produzido a partir da fundação do IHGB, qual seja, a carga nacionalista da fundação do Estado. Conforme Armelle Enders,

[...] de fato, esperavam-se dos historiadores não apenas grandes diretrizes capazes de unir o passado e o futuro dos povos, mas também resultados práticos, imediatamente aplicáveis à política nacional, aos interesses econômicos e aos litígios fronteiriços (ENDERS, 2014, p. 86).

O pragmatismo do trabalho de investigação histórica não seria resolvido senão por meio de uma solução eficiente tanto no sentido de apresentar planos de ação política quanto no de efetivamente orientar, na esteira do discurso letrado da época, os mecanismos de legitimidade do saber que advinha daquela investigação. Cláudia 
Entre antigos e modernos: escrita da história e lições morais no Brasil...

Callari considera, no que chamou de momento singular da historiografia brasileira, a situação das concepções no âmbito do IHGB como uma confusão entre a tradição e a memória coletiva e a história propriamente dita. Ainda de acordo com a historiadora, a permanência do topos historia magistra vitae, forte nos primeiros anos que se seguiram à fundação, mas ainda presentes nas décadas posteriores e mesmo no início do século XX, apenas reforça os interesses na definição do Estado nacional (CALLARI, 2001, p. 74).

Não exatamente um quadro no qual se confundia tradição e história, mas a premência do político talvez ajude a explicar a longevidade da marca clássica na historiografia do IHGB. Essa preponderância acabava por constituir certo alargamento da concepção de história, que não se conformava em inventariar os registros do passado, mas deveria ainda atribuir sentido àquilo que se encontrava livre em suas ações pretéritas. Era o que concluía Cunha Barbosa em outro trecho de seu Discurso:

A prossecução do meu discurso me faz chegar a um ponto que, designando bem claramente a grande utilidade que se pode colher dos estudos históricos e geográficos, marca por isso mesmo uma época gloriosa em nossa pátria, da qual se descobre a honrosa estrada que podem melhor seguir aqueles dos nossos patrícios em cujos peitos palpitam corações animados pelo amor da glória literária. Eles, de certo, farão o melhor uso dos seus estudos sobre a história da pátria, expurgada de tantos erros, enriquecendo os seus espíritos de conhecimentos interessantíssimos, que lhes sirvam nos empregos a que forem chamados pelos votos dos seus concidadãos. Da combinação dessas ideias, assim adquiridas, nascerão princípios de que produzam novos conhecimentos, que ilustrem a carreira da sua vida, tornando mais profícuos os seus serviços em benefício da pátria. Não duvidamos, senhores, que as melhores lições que os homens podem receber lhes são dadas pela história (BARBOSA, 1839, p. 13).

As lições dadas pela história tinham o nítido papel de valorizar, em simultâneo, o saber sobre o passado pátrio e o esforço daqueles 
que ora se dedicavam à pesquisa do conhecimento histórico. As oportunidades criadas pela fundação do IHGB são argumento reafirmado em diversas passagens do texto supracitado. A dimensão disciplinar está marcada, evidentemente, por condições que surgiam ao ofício do historiador. Como se pode observar, sem comprometer a importância da tradição erudita que circunscreve a historiografia do século XIX, a atenção aos ditames do presente oitocentista pode auxiliar na compreensão da presença dos antigos nos textos dos sócios da academia imperial fundada em 1838.

Aparentemente, menor era o caráter de confusão entre memória e história. Tratava-se tanto mais de opção adequada ao projeto nacional à manutenção de elementos clássicos, há muito circulantes nas academias de história e, posteriormente, na imprensa periódica e literária europeia. Além de Cícero, podemos observar a marca de Plutarco na proposta biográfica registrada no texto de Cunha Barbosa:

$\mathrm{Na}$ vida dos grandes homens aprende-se a conhecer as aplicações da honra, a apreciar a glória e a afrontar os perigos, que muitas vezes são causas de maior glória. O livro de Plutarco (diz o barão de Morogues), é uma excelente escola do homem, porque oferece em todos os gêneros os mais nobres exemplos de magnanimidade; aí se encontra descoberta toda a antiguidade; cada homem célebre aí aparece com seu gênio, com seus talentos, com suas virtudes e com a influência que exercera sobre seu século; aí se aprende como o gênio dá movimento a povos inteiros por suas leis, por suas conquistas, por sua eloquência, aí se conhece a sabedoria dos desígnios, umas vezes profundamente concebidos e amadurados pelos anos, outras vezes como inspirados, admitidos e executados a um só tempo com a energia que domina os maiores obstáculos; aí vidas brilhantes e mortes ilustres ensinam a amar a glória, a apreciar as suas causas, a prever seus resultados, e a acautelarmo-nos daqueles perigos que a seguem como sombras, porque (diz M. Thomaz) os homens que pesam sobre o universo também lutam com o seu próprio peso; logo após a glória acham-se frequentemente ocultos o desterro, o ferro e o veneno (BARBOSA, 1839, p. 14-15). 
A leitura do excerto ora exposto evidencia o caráter pedagógico do projeto aberto pelo IHGB. Entretanto, não exclusivamente indicador de matiz moral, mas cívico. Especificamente, pode-se dizer que a história - ao abarcar componentes particulares como as narrativas de vidas - seguia a aglutinar a multiplicidade de aspectos do mundo político. "Escola do homem", as biografias poderiam servir para a educação dos brasileiros, nesse momento inicial da investida historiográfica. As etapas da vida humana, do nascimento à morte, quando permeadas por contribuições para a imagem da nação, poderiam compor relatos que, mais que meros apontamentos particulares, "[...] encontra[riam] descoberta toda a antiguidade". Considerando a apropriação plutarqueana demarcada no texto de Cunha Barbosa, uma vez mais se evidencia uma aporia do discurso histórico sobre a nação então posto em andamento: ao mesmo tempo em que pretendiam dar características específicas ao Brasil, muitas vezes sofisticadas quando se consideram as diversas exigências e os impedimentos à narrativa do passado nacional, os envolvidos nessa tarefa não prescindiam da inclusão da história brasileira em uma perspectiva mais ampla e, por isso, mais apreensível.

Maria da Glória de Oliveira sintetizou de maneira bastante eficaz a convocação da biografia no espaço letrado oitocentista, com destaque para a vasta produção desse gênero ligada ao IHGB. Segundo essa historiadora,

No longo processo de sutura do mosaico de identidades coletivas que marcou a cultura histórica do Brasil no século XIX, historiografia e biografia compartilharam não apenas os propósitos de fixação dos fatos e nomes memoráveis, de modo que eles espelhassem os valores políticos e morais da nação, mas também sustentaram as ambições de verdade e fidedignidade na representação do seu passado (OLIVEIRA, 2011, p. 172).

O retorno às páginas do periódico do IHGB, sem dúvida, reforça a conclusão apresentada no trecho anteriormente exposto. Ao lado disso, é importante lembrar que esse órgão surge e é posto em funcionamento dentro do modelo monárquico, este ligado por 
laços efetivos aos parâmetros de antigo regime. Esse tipo de exigência nobiliárquica não seria preterida, o que reforça a hipótese do uso político e retórico da menção a Plutarco. Contudo, tal como também evidencia o trabalho de Oliveira, o predomínio de agendas políticas não impediu que a presença de autores e de modelos antigos atingisse a escrita da história em seus trâmites epistemológicos. Ao contrário, boa parte dos princípios e das regras apresentadas a partir de remissões a Cícero, Plutarco e suas obras indicava, de fato, não somente o pragmatismo do conhecimento histórico então em elaboração, mas seu estatuto e sua legitimidade.

Nesse sentido, Temístocles Cezar encaminha sua análise sobre a valorização do saber histórico e da construção do passado nacional no Oitocentos a partir da hipótese de certo câmbio de autoridade entre os modelos antigos e a historiografia moderna (CEZAR, 2011a). Cezar traz por premissa a perspectiva de que os historiadores oitocentistas vinculados ao IHGB optaram por seus pontos de partida dentre as possibilidades legadas pela tradição. A partir disso, a referência aos antigos

[...] não exerce apenas um papel de fundamento retórico - um ideal a imitar ou a evitar -, mas também um papel de figura de autoridade que, em última instância, atribuirá à cultura histórica nacional uma configuração com base científica e/ou erudita e literária, ou ao contrário, uma base pseudocientífica e/ou pura e simplesmente eloquente (CEZAR, 2011a, p. 50-51).

Como já foi lembrado pelo mesmo historiador em outro texto, apesar desse aspecto de normatização do discurso histórico, textos como o de Januário da Cunha Barbosa, entre outros, reafirmavam as limitações e dificuldades da escrita da história na operação com as categorias de antigo e de moderno (CEZAR, 2011b, p. 94).

Valdei Araujo, por sua vez, ressaltou as alterações conceituais ocorridas entre a geração da Independência e os letrados ocupados do projeto de historiografia nacional a partir da década de 1830 . Segundo o historiador, a permanência das menções aos antigos teria a ver com a resistência da formação retórica de boa parte 
Entre antigos e modernos: escrita da história e lições morais no Brasil...

desses homens. Ao contrário do conceito de literatura advindo do movimento romântico, que pretendeu uma separação direta com a tradição clássica, "[...] a revista do IHGB e a historiografia brasileira da época parecem demonstrar que o rompimento com essas imagens não foi condição determinante para o estabelecimento de nova historiografia [...]” (ARAUJO, 2008a, p. 150). Posteriormente, Araujo enfatizou a hipótese de que teria havido uma adaptação do topos historia magistral vitae ciceroniano. Buscando diferenciar a concepção de história dominante entre as histórias filosóficas do século XVIII e as filosofias da história oitocentistas e seus respectivos ajustes, destaca:

Ao mesmo tempo, o etapismo das filosofias da história permitiu tirar lições do passado, já que pela sua análise é possível vislumbrar o futuro, mesmo que esse já não fosse concebido em termos de repetição do passado. Assim, o topos pode ser adaptado a esse novo tipo de lição histórica: é possível aprender com o passado, mas não imitá-lo, como é fundamental na concepção ciceroniana. Em resumo, o simples uso retórico dos topoi ciceronianos não qualifica uma concepção de história como pré-moderna, pois o fundamental seria entender quais os procedimentos necessários para aprender com a história (ARAUJO, 2008b, p. 55, grifos do autor).

Reunidas, as diversas abordagens expostas até aqui fornecem importantes elementos para a compreensão da resistência de modelos antigos na escrita histórica fabricada no IHGB. Sem exceção, as leituras evidenciam, em maior ou menor grau, o inarredável peso do político, confirmado inclusive pelos conceitos que sustentam os argumentos sobre o tema (identidade, autoridade, filosofias da história). Como e se ocorrem dissociações mais nítidas entre o sentido do diálogo com os antigos para a história sob o prisma disciplinar e o uso dos antigos direcionado ao caráter pedagógico e cívico é algo a ser verificado. Para além de propor uma diferenciação entre condicionamentos epistemológicos e fins de divulgação do saber histórico, será possível avançar no que diz respeito às concepções temporais desses letrados. Levar em consideração a historicidade do 
modelo monárquico e sua chancela nesse processo é algo pertinente. Restará, além disso, elucidar até que ponto "seguir Cícero" e buscar a verdade poderia corresponder, na prática, a eliminar perspectivas alternativas acerca do presente e incentivar a manutenção de um determinado passado e também seu monopólio.

\section{A história que serve é uma história serva?}

O papel pedagógico que se exigia da história produzida no IHGB é ideia constantemente retomada em praticamente todos os estudos historiográficos cujos objetos consistem nos textos vinculados direta ou indiretamente àquele órgão. Tanto no Discurso de fundação, proferido por Januário da Cunha Barbosa, como nos registros mais amplos de interação com academias europeias, essa dimensão do conhecimento histórico em meados do século XIX pode ser considerada determinante para a constituição disciplinar e para a definição de seu executor de ofício. Como destaca Valdei Lopes de Araujo, "[...] essa opção pelo ensino e pela divulgação guarda uma certa coerência com o movimento ilustrado luso-brasileiro, que, ao menos em teoria, privilegiava a divulgação do conhecimento" (ARAUJO, 2008a, p. 144). Tendo em conta esse aspecto, é pertinente retomar outros escritos fundamentais que apareceram nos primeiros anos do Instituto e que encaminham, por outras frentes, o problema geral da permanência de concepções antigas na escrita histórica oitocentista.

Pode-se, de imediato, alternar a ideia até aqui desenvolvida acerca da sujeição da história às exigências do presente da época. Até que ponto a presença dos antigos, mais que apenas harmonizar a manutenção da ordem política por meio da sustentação de um conhecimento que se queria legitimador, também não conduziu à aceleração da crítica que promoveria o historiador a uma figura pública de relevância, para além das posições definidas no período regressista (no Brasil) e regenerador (em Portugal)? Nem serva do presente, nem serva do passado: o impreciso conceito de história ganhava itinerários que, em muitos sentidos, levam a percepções 
Entre antigos e modernos: escrita da história e lições morais no Brasil...

difusas acerca das consequências das escolhas dos homens que planejavam a história do Brasil no âmbito do IHGB.

A necessidade de se dar ordem à história do Brasil, presente no texto inaugural de Cunha Barbosa, motivou discussões que, é permitido dizer, circunscreviam basicamente a totalidade dos dilemas políticos e historiográficos comuns à década de 1830. Poucas semanas após a sessão de abertura, o marechal Raimundo José da Cunha Mattos propusera uma "Dissertação acerca do sistema de escrever a história antiga e moderna do Brasil” (MATTOS, 1863, p. 121-143). Na verdade, uma primeira versão do texto de Cunha Mattos fora apresentada no dia quinze de dezembro de 1838, no IHGB, sob o título Quais são as verdadeiras épocas da História do Brasil?, sendo outra exposta já com o título da referência aqui utilizada; como também se pode observar, ele só foi editado e publicado 25 anos depois.

A importância dos debates levantados pelo discurso do marechal apareceu indicada na apresentação do texto, pois, como observa Temístocles Cezar, o próprio autor fez questão de indicar que se tratava de versão revista após contribuições de outros sócios (CEZAR, 2011b, p. 112). Desde o início, Cunha Mattos expusera sua opinião negativa sobre a possibilidade de se escrever uma história geral do Brasil:

Pela parte que me toca declaro francamente que se a sorte ou a votação por escrutínio recair em mim para trabalhar in solidum ou como colaborador em uma empresa tão gigantesca, eu me ostentarei inabilitado, e recusarei aceitar essa honrosa comissão, para não ter de representar um papel desagradável e muito em desabono do Instituto Histórico (MATTOS, 1863, p. 122).

Essa ideia seria constante à maioria dos sócios. A sensação presente entre os membros era realmente aquela que se dirigia para a inauguração de uma forma diferenciada de se construir o tempo histórico nacional. Efetivamente, Cunha Mattos ficaria fora da continuidade de debates relativos ao tema em função de sua morte, ocorrida poucos dias após a leitura do texto, como atesta a ata da sexta sessão do IHGB, datada de dois de março de 1839 (Revista do IHGB, 1839, p. 49-50). 
De todo modo, a fala de Cunha Mattos deixava ditos alguns limites que impediam o início de um trabalho histórico mais geral. O propósito primário do IHGB estava definido em reunir documentação distribuída pelas províncias e mesmo fora do império. Desse modo, enfatizava:

Como será possível escrever uma história filosófica do povo do Brasil antes de levar ao cadinho da censura mais severa o imenso fardel de escritos inexatos, insulsos, indigestos, absurdos e fabulosos anteriores ao ano de $1822 \mathrm{em}$ que unicamente se imprimia em Portugal, e raríssimas vezes no Brasil, aquilo que um governo desconfiado, uma inquisição intolerante, um Ordinário sem critério, uma mesa da comissão sobre a censura dos livros permitia que fosse publicado? Como será possível escrever a história filosófica do Brasil tomando por farol os livros estrangeiros impressos antes da declaração da independência do império? (MATTOS, 1863, p. 122-123).

É oportuno observar a dupla crítica presente no excerto ora exposto. Por um lado, recriminavam-se as incorreções provocadas pelas impressões demarcadas à distância, vindas quase que exclusivamente de Portugal no longo período colonial; de outro, a condenação da instituição inquisitorial, que filtrava de forma inadequada as notícias sobre o Brasil. Nessa breve passagem, estavam redimensionadas duas ideias diretamente ligadas ao conceito de história na época, quais sejam, a defesa de um ponto de vista nacional, sem que este viesse a comprometer justamente a segunda ideia a ser ressaltada: o lugar da crítica que deveria vir da investigação acadêmica, ainda que esta estivesse diretamente ligada ao poder político e religioso. Tais premissas criavam alguma identidade ao mosaico de proposições que emergiam no IHGB.

No que diz respeito a dois dos pontos levantados, a saber, a visão estrangeira e a participação da religião do Estado imperial, o historiador inglês Robert Southey, autor de uma precoce História do Brasil, datada de 1810, torna-se alvo de elogios e críticas por parte de Cunha Mattos: 
O melhor de todos aqueles escritores, o sábio Southey, a todo $\mathrm{o}$ instante nos lança em rosto a nossa incapacidade; e fere-nos na parte mais sensível das nossas opiniões, atacando sem rebuço a crença religiosa, em que vivemos qualificando-nos de idólatras fanáticos, supersticiosos e de perpetradores de toda a espécie de maldade, por acreditarmos que a confissão e a absolvição purificam-nos perante Deus e os homens! Quantas reflexões poderemos nós fazer a respeito da crença e da moral desses estrangeiros que não têm a confissão nem absolvição supersticiosa dos brasileiros, e apesar disso cometem crimes de natureza tão atroz como os que praticam em todos os lugares do universo! (MATTOS, 1863, p. 123, grifos do autor).

Esse tipo mais geral de posicionamento crítico, que participava dos debates sobre os caminhos possíveis para a escrita de uma história brasileira, evidencia as diretrizes anteriormente mencionadas no que se relaciona à questão nacional da investigação do passado e seu envolvimento direto com a defesa da política imperial. Como se pode observar desde já, mesmo em texto como esse de Cunha Mattos, cuja remissão direta aos antigos não é uma marca (exceto em um ponto na parte final), a história faz as vezes de embate político, sem, contudo, negligenciar a centralidade das discussões disciplinares. ${ }^{2}$ As consequências da história da monarquia portuguesa, sua sujeição à coroa castelhana e o controle administrado pela inquisição são justificativas trazidas para a explicação dos limites das ciências e das artes em Portugal e, por conseguinte, no Brasil (MATTOS, 1863, p. 125-126). É importante sublinhar que, se o império buscava contar a sua história em terras americanas, ao mesmo tempo, Portugal tinha pretensões de "regenerar" sua nação a partir do estudo do passado e da crítica a todo e qualquer aspecto que pudesse ser relacionado à decadência percebida na época. Tais reconstituições e argumentos corroboram a visão desses primeiros registros do IHGB como comprovados textos fundadores da disciplina histórica, sem negligenciar as outras formas da crítica histórica de períodos anteriores. 
Chama atenção um ponto específico da fala de Cunha Mattos, excerto este a partir do qual o marechal expressa sua concepção geral da história e de seus meios de fabricação:

\begin{abstract}
A história abrange todos os ramos do conhecimento humano: pode ser geral ou particular, e divide-se em seções principais, que são subdivididas em particulares ou especiais. Ela em a matéria, ordem, e estilo deve ser escrita por um modo harmonioso, agradável, conciso, decente, exato e o mais claro que for possível; e o fim principal da história política e civil, é encaminhar os homens à prática das virtudes e ao aborrecimento dos vícios para que daí resulte o bem-estar das sociedades (MATTOS, 1863, p. 137).
\end{abstract}

Essa ocupação generalizada da história, responsável por “todos os ramos do conhecimento", tornava-se impreciso o novo estatuto desse saber antigo (o mesmo ocorrendo com a definição de seu produtor), permitia, entretanto, que aspectos do presente dialogassem constantemente com as informações e opiniões sobre o passado. A exigência didática à historiografia, por sua vez, delimitava algo além da pertinência de sua aplicação pedagógica. Nessa perspectiva, pode-se pensar que o chamado uso político do passado, no que se refere ao seu momento de fundação como disciplina, participou também da definição da série de aspectos epistemológicos que vem sendo analisada em suas particularidades desde, no mínimo, os anos 1980 pela historiografia brasileira.

Cunha Mattos reservou ainda, em seu texto, espaço significativo para a apresentação de uma divisão cronológica para a história do Brasil. Declarando-se afinado com a proposta ensejada no discurso de Januário da Cunha Barbosa, defendeu a seguinte divisão tripartite: a história dos aborígines e autóctones, o longo período de administração colonial e, por fím, os acontecimentos importantes do império desde a independência. $\mathrm{O}$ marechal já antecipava as dúvidas quanto à referida subdivisão, em especial às características da primeira e terceira partes (MATTOS, 1863, p. 129). Percebe-se na argumentação uma diferenciação que não prescinde de comparação entre antigos e modernos. Conforme Cunha Mattos, as 
Entre antigos e modernos: escrita da história e lições morais no Brasil...

dificuldades para a construção da história indígena tangiam à falta de documentos e informações secundárias realmente verificadas. Essa fase "fabulosa" da história brasileira seria própria de outra época, visto que os historiadores do passado não resguardavam o mesmo compromisso com a verdade dos modernos:

Se houvesse de escrever a história dos aborígines do Brasil, ver-me-ia tão embaraçado como todos os que em épocas mais ou menos remotas têm dissertado a respeito deles. Muitos historiadores improvisaram, e quiseram mostrar como fatos certos e evidentes, aqueles que nasciam de símplices conjecturas. A ciência da linguística que agora começa a cultivar-se, é a que há de mostrar-nos a origem das tribos ou nações; nem esperemos que os homens que não possuem monumentos de séculos mais ou menos remotos, nos digam se se reputam autóctones, ou se vieram de terras longínquas estabelecerem-se nos lugares em que ora se acham (MATTOS, 1863, p. 133).

Os trabalhos anteriormente citados de Temístocles Cezar e Rodrigo Turin evidenciam, ao enfatizarem questões complementares, aspectos dessas injunções referentes à formação da população, com destaque para a presença indígena. Ambos avançam na análise das alternâncias na temporalidade da época a partir desta reorganização dos saberes e de suas finalidades em meados do Oitocentos. Fundamentalmente, o que se deve observar é o parâmetro de que a conhecida sujeição da disciplina histórica ao grande sentido político exterior, qual seja, a nação, não eximia os letrados do século XIX de serem responsáveis por certa alternância epistemológica que resultava em efetivas mudanças sociais, à revelia das limitações variadas engendradas no contexto de fundação do IHGB. Dito de outra forma, a discussão geral deste artigo, no tocante à presença de autores antigos na historiografia do Brasil oitocentista, entre outras ponderações, sugere que o espaço compartilhado por antigos e modernos pode ser visto como espaço político, ambiente onde determinados compartimentos seriam aos poucos estabelecidos, sem qualquer direção estrita. Ainda assim, a questão de fundo político não impedia formulações de conotação disciplinar. 
Ainda na tentativa de evitar uma análise excessivamente esquemática daquela presença, retomar o concurso promovido pelo IHGB, em novembro de 1840, com o intuito de incentivar seus sócios a apresentarem planos de escrita para a história do Brasil, pode permitir encetar algumas observações sobre o debate relacionado ao tempo histórico pensado para a história nacional e o tema geral deste artigo, dedicado à marca dos antigos no Instituto. $\mathrm{O}$ texto vencedor no referido concurso foi escrito pelo sábio bávaro Carl Friedrich Philip von Martius, intitulado Como se deve escrever a história do Brasil (MARTIUS, 1844). Apresentado em 1843, o plano historiográfico dividia-se em quatro partes, sendo a primeira chamada "ideias gerais sobre a história do Brasil” e as três subsequentes dedicadas, respectivamente, a indígenas, portugueses e africanos. Partidário de uma história filosófica, concepção em voga na Europa, Martius deixa nítida a finalidade pedagógica e política de sua proposta:

Portanto devia ser um ponto capital para o historiador reflexivo mostrar como no desenvolvimento sucessivo do Brasil se acham estabelecidas as condições para o aperfeiçoamento de três raças humanas, que nesse país são colocadas uma ao lado da outra, de uma maneira desconhecida na história antiga, e que devem servir-se mutuamente de meio e de fim (MARTIUS, 1844, p. 384).

É interessante observar que, apesar de essa unidade entre as raças defendida por Martius ir ao encontro de uma concepção nacional, o ordenamento das seções, partindo do legado indígena, passando pelos portugueses até chegar aos escravos africanos, demonstra certa organização que atendia à cronologia, mas também ao tempo da história que se pretendia contar, em termos, inclusive, metodológicos, no que diz respeito à narrativa histórica. Tal detalhe foi observado por Cezar: "[...] esta ordem é por si só reveladora. Ela sinaliza um tempo: os índios chegaram antes dos portugueses. Este dado, naquela época, não constituía uma evidência" (CEZAR, 2003, p. 182). Além disso, cada uma das partes dedicadas a um dos povos foi apresentada com as especificidades exigidas pela investigação de sua história. No que dizia respeito ao passado indígena, a ideia 
repisada da necessidade de se estudarem suas línguas foi lembrada por Martius, ao passo que a história dos portugueses seguiria o caminho dos documentos escritos e das viagens ou seus relatos. Embora aparentemente óbvias, tais sinalizações orientaram boa parte das investigações que sucederam os primeiros debates no IHGB. Fundamentalmente, muitos dos grandes temas que ocuparão os letrados dedicados à história ao longo do século XIX - e também nas primeiras décadas do século XX - estão sugeridos explícita ou implicitamente nesse projeto escrito por Martius.

Apesar de não ser uma característica muito presente no texto em questão, em sua parte final, a remissão aos antigos ingressa na argumentação de Martius. Em longa passagem, na qual sublinha a importância das viagens para a boa descrição narrativa de diversos elementos do povo e da natureza brasileira, o autor do plano historiográfico menciona o exemplo de Heródoto. No mesmo trecho, destaca-se outro efeito previsto para as obras dedicadas à história do Brasil, isto é, o interesse dessas descrições para o leitor europeu (MARTIUS, 1844, p. 401). Contudo, o que importa ressaltar diz respeito ao papel pedagógico e político da história, conforme as palavras do sábio:

Por fim devo ainda ajuntar uma observação sobre a posição do historiador do Brasil para com a sua pátria. A história é uma mestra, não somente do futuro, como também do presente. Ela pode difundir entre os contemporâneos sentimentos e pensamentos do mais nobre patriotismo. Uma obra histórica sobre o Brasil deve, segundo minha opinião, ter igualmente a tendência de despertar e reanimar em seus leitores brasileiros amor à pátria, coragem, constância, indústria, fidelidade, prudência, em uma palavra, todas as virtudes cívicas. O Brasil está afeito em muitos membros de sua população de ideias política imaturas. Ali vemos republicanos de todas as cores, ideólogos de todas as qualidades. É justamente entre estes que se acharão muitas pessoas que estudarão com interesse uma história de seu país natal; para eles, pois, deverá ser calculado o livro, para convencê-los por uma maneira destra da inexequibilidade de seus projetos 
utópicos, da inconveniência de discussões licenciosas dos negócios públicos, por uma imprensa desenfreada, e da necessidade de uma monarquia em um país onde há um tão grande número de escravos. Só agora principia o Brasil a sentir-se como um todo unido (MARTIUS, 1844, p. 401-402).

Esse excerto, embora longo, merece destaque por encaminhar a perspectiva com a qual trabalho ao longo de todo o artigo. A participação de autores antigos na historiografia produzida pelo IHGB pode ter diversas leituras, muitas vezes não necessariamente antagônicas ou divergentes. A prova disso são as hipóteses levantadas nos últimos anos pelos trabalhos citados anteriormente. Todavia, a proposta que gostariamos de evidenciar tange ao papel de elo discursivo exercido pela menção aos modelos antigos, elo esse entre política e discurso histórico. A história, como mestra do futuro, mas também do presente, opera como um dos instrumentos mais efetivos na tarefa de alimentar o civismo. Percebe-se a clareza do caráter propositivo de uma investida como a que conduziu à fundação do IHGB, ou seja, o plano de Martius não deixa dúvida acerca da consciência do caráter original de seu plano de escrita.

Cabe ponderar, neste ponto, que, apesar do demarcado princípio como tal empreitada era vista, o autor bávaro fala tanto em despertar quanto em reanimar as virtudes cívicas no país. Nesse detalhe parece haver sinal de uma diferença, que trata da perspectiva pela qual a história do Brasil era examinada pelo autor estrangeiro. Podem-se perceber, no mínimo, três âmbitos políticos e dois contextos historiográficos: Brasil recém-independente, Portugal do período pós-revoluções liberais e o espaço letrado alemão. A riqueza de um texto como o de Martius constitui, justamente, a possibilidade de se examinarem as relações entre regimes de historicidade e regimes políticos, considerando, evidentemente, espaços e tempos diversos. ${ }^{3}$ Inclusive, no tocante à expectativa de leitores, o texto fixa os objetivos de atingir e sensibilizar o leitor "brasileiro", sem esquecer o atrativo do tema aos europeus. Não é despropositado notar aqui preocupações políticas e letradas em perfeito paralelo.

Merece ainda alguma atenção a presença, mesmo que mínima, de elementos concernentes ao topos história magistral vitae. Mais 
Entre antigos e modernos: escrita da história e lições morais no Brasil...

que um registro erudito, quase um agregador cosmopolita nas posições de muitos homens de letras, como já foi visto anteriormente, uma resolução única ou definitiva para esse fato parece-me pouco provável. Assim, importa levar em conta as diferenças entre os contextos políticos brasileiro e português, especialmente na tentativa de entender quais as possíveis prerrogativas dessas repetições. Em contrapartida, se o pragmatismo de Martius com relação ao assunto parece bastante evidente, o outro texto que foi apresentado para concorrer ao prêmio proposto pelo IHGB não se tratava de uma atualização da fórmula, mas de um simples empréstimo, como se fossem os registros antigos ferramentas a facilitarem o trabalho dos historiadores oitocentistas.

O texto em questão é o de Julio de Wallenstein, intitulado Memória sobre o melhor plano de se escrever a história antiga e moderna do Brasil (WALLENSTEIN, 1882, p. 159-160). Composto por apenas duas laudas, a sugestão era a seguinte:

[...] o plano, que parece mais acertado, de se escrever a história do Brasil é seguramente o mesmo, que seguiu Tito Lívio, João de Barros e Diogo do Couto, isto é, pelo sistema das décadas, narrando-se os fatos acontecidos dentro de períodos certos (WALLENSTEIN, 1882, p. 159).

Dessa forma, o modelo de sistematização correspondia muito intimamente ao regime dos anais, encadeados cronologicamente, registros do que, no esparso do tempo, poderia ser ordenado. Não havia pretensão de esgotar os fatos do passado, uma vez que

[...] sempre hão de existir na falha dos fatos, que se não memorarão, como de ordinário acontece, quando principia um tempo histórico, que se vai descrever séculos depois; porém, para clareza e percepção, parece que este método das décadas é o mais preferível (WALLENSTEIN, 1882, p. 159).

Nessa senda, o objetivo era, segundo Wallenstein, garantir clareza à narração histórica. 
Ainda que o autor do texto tenha proposto a aplicação direta da forma antiga, a narrativa por décadas não era capaz de dar conta das particularidades da história brasileira. "Neste sentido, antes que se principiem a narrar os fatos históricos, deve preceder uma introdução descritiva das nações indígenas, que habitavam as costas do Brasil na ocasião dos descobrimentos" (WALLENSTEIN, 1882, p. 159). Esse modelo, eminentemente político, não contemplava as alterações pelas quais passara a própria história como conhecimento. A comprovação disso foi o parecer profundamente negativo ao texto, escrito, em 1847, por Francisco Freire Allemão, Thomaz Gomes dos Santos e monsenhor Joaquim da Silveira, como lembra Temístocles Cezar. Ainda conforme este historiador:

[...] não se trata apenas de uma recusa de modelos antigos da historiografia, mas da afirmação de uma nova abordagem histórica, a história filosófica, perspectiva presente no IHGB desde a sua fundação [...] e que também orienta o plano vencedor de Martius (CEZAR, 2003, p. 174-175, grifos do autor).

Havia, portanto, limites à participação dos antigos e ressalvas à sua utilidade na lida com o passado. Afinal, muitos dos problemas modernos não estavam colocados aos autores da antiguidade e, desse modo, cabia aos leitores do século XIX o rearranjo das possibilidades e limites apontados por aqueles.

\section{BETWEEN THE ANCIENT AND THE MODERN: HISTORY WRITING AND MORAL LESSONS IN BRAZIL IN THE $19^{\text {TH }}$ CENTURY}

Abstract: This paper aims to examine the presence of ancient authors in the historiographical production of the Brazilian Historic and Geographic Institute (IHGB), founded in Rio de Janeiro, in the middle of the $19^{\text {th }}$ century. In order to do that, we have considered some texts published in Revista do IHGB in the light of the current debate about this topic. Regarded as seminal sources of the history of historiography, an approach that supports this analysis, such writings provide important elements to the debate, which is still open. In this sense, we 
Entre antigos e modernos: escrita da história e lições morais no Brasil...

have argued that, despite their participation in the long process of establishment of modernity and their both epistemological and rhetorical participation, the moral aspects provided by the ancient authors operated as a discursive link between the power of the imperial State and the emerging history discipline. Keywords: History of historiography. Ancient and Modern. IHGB.

\section{Notas}

${ }^{1}$ Valdei Araujo observou a frequente remissão às academias letradas nos primeiros textos do Instituto, como, justamente, o "Programa Histórico" assinado por José Feliciano Fernandes Pinheiro (ARAUJO, 2008a, p. 148).

${ }^{2}$ Para a passagem na qual Heródoto, Dionísio e Plutarco são referenciados, ver (MATTOS, 1863, p. 138-139).

${ }^{3}$ Foi o texto de uma conferência proferida por François Hartog que, em alguma medida, conduziu minha leitura neste artigo, mas principalmente neste ponto da análise. Essa possibilidade de apropriação do instrumento heurístico que se define, a partir do trabalho do historiador francês, como "regimes de historicidade", ainda foi pouco aprofundada. A historiografia americana, por sua própria condição de emergência, permite um vasto percurso investigativo nesse sentido (HARTOG, 2006, p. 21-23).

\section{Referências}

ARAUJO, Valdei Lopes. A experiência do tempo: conceitos e narrativas na formação nacional brasileira (1813-1845). São Paulo: HUCITEC, 2008a.

. História dos conceitos: problemas e desafios para uma leitura da modernidade ibérica. Almanack Braziliense, n. 7, maio 2008b, p. 47-55.

ATA da 6- sessão em 2 de março de 1839. Revista do IHGB, 1839, p. 49-50.

BARBOSA, Januário da Cunha. Discurso. Revista do IHGB, Rio de Janeiro, 1839, p. 9-18.

BENJAMIN, Walter. Experiência e pobreza. In: Magia e técnica, arte e política: ensaios sobre literatura e história da cultura. Obras escolhidas. Vol. 1. São Paulo: Brasiliense, 1994, p. 114-119.

BREVE NOTÍCIA sobre a creação do Instituto Histórico e Geographico Brazileiro. Revista do IHGB, Rio de Janeiro, 1839.

Anos 90, Porto Alegre, v. 25, n. 47, p. 253-278, jul. 2018 
CALLARI, Cláudia. Os Institutos Históricos: do patronato de D. Pedro II à construção de Tiradentes. Revista Brasileira de História, São Paulo, v. 21, n. 40, 2001, p. 59-83.

CEZAR, Temístocles. Como devia ser escrita a história do Brasil no século XIX. Ensaio de história intelectual. In: PESAVENTO, Sandra Jatahy (Org. et al.). História cultural: experiências de pesquisa. Porto Alegre: UFRGS, 2003, p. 173-208.

. L'écriture de l'histoire au Brésil au XIX siècle. Essai sur l'utilisation des modeles anciens et modernes de l'historiographie. Historiografias, v. 2. juil./déc 2011a, p. 45-65.

. Lições sobre a escrita da história: as primeiras escolhas do IHGB. A historiografia brasileira entre os antigos e os modernos. In: NEVES, Lucia Maria Bastos Pereira das et. al. Estudos de historiografia brasileira. Rio de Janeiro: Editora FGV, 2011b, p. 93-124.

ENDERS, Armelle. Os vultos da nação: fábrica de heróis e formação dos brasileiros. Rio de Janeiro: Editora FGV, 2014.

GUIMARÃES, Manoel Luiz Salgado. Entre o amadorismo e o profissionalismo: as tensões da prática histórica no século XIX. Topói, Rio de Janeiro, dez. 2002, p. $184-200$.

HARTOG, François. Tempos do mundo, história, escrita da história. In: GUIMARÃES, Manoel Luiz Salgado (Org.). Estudos sobre a escrita da história. Rio de Janeiro: 7Letras, 2006, p. 15-25.

HEGEL, Geog W. F. A razão na história: uma introdução geral à filosofia da história. São Paulo: Centauro, 2001.

MAGALHÃES, D. J. Gonçalves de. Os indígenas do Brasil perante a história. Revista do IHGB. Rio de Janeiro, 1860.

MARTIUS, Carl Friedrich Philip von. Como se deve escrever a história do Brasil. Revista do IHGB, 1844, p. 381-403.

MATTOS, Raimundo José da Cunha. Dissertação acerca do sistema de escrever a história antiga e moderna do império do Brasil. Revista do IHGB, 1863, p. 121-143.

OLIVEIRA, Maria da Glória de. Escrever vidas, narrar a história: a biografia como problema historiográfico no Brasil oitocentista. Rio de Janeiro: Editora FGV, 2011.

PAYEN, Pascal. A constituição da história como ciência no século XIX e seus modelos antigos: fim de uma ilusão ou futuro de uma herança? História da Historiografia. Ouro Preto, n. 6, mar. 2011, p. 103-122. 
Entre antigos e modernos: escrita da história e lições morais no Brasil...

SILVEIRA, Cássia Daiane Macedo da; SANTOS, Evandro. Regeneração e decadência: história, literatura e os usos do passado e do presente no Portugal oitocentista. Revista História e Cultura, Franca, v. 3, n. 1, 2014, p. 90-104.

TURIN, Rodrigo. Entre "antigos" e "selvagens": notas sobre os usos da comparação no IHGB. Revista de História, edição especial, São Paulo, 2010, p. 131-146.

W WALLENSTEIN, Julio de. Memória sobre o melhor plano de se escrever a história antiga e moderna do Brasil. Revista do IHGB, 1882, p. 159-160.

WEHLING, Arno. Estado, história, memória: Varnhagen e a construção da identidade nacional. Rio de Janeiro: Nova Fronteira, 1999.

. O historismo e as origens do Instituto Histórico. In: $A$ invenção da história: estudos sobre historicismo. Rio de Janeiro: Editora Central da Universidade Gama Filho; Niterói: Editora da Universidade Federal Fluminense, 1994, p. 151-168.

Recebido em: 01/06/2017.

Aprovado em: 10/10/2017. 